\title{
The End of the American Dream? Inequality and Segregation in US cities
}

Alessandra Fogli and Veronica Guerrieri

\author{
EIEF Rome 2016
}




\section{Motivation}

- Large increase in inequality in US over the last 40 years.

- This paper explores the dynamic implications of high inequality: 


\section{Motivation}

- Large increase in inequality in US over the last 40 years.

- This paper explores the dynamic implications of high inequality:

- How does high inequality affect residential and education choices? 


\section{Motivation}

- Large increase in inequality in US over the last 40 years.

- This paper explores the dynamic implications of high inequality:

- How does high inequality affect residential and education choices?

- How do these choices in turn affect mobility and future inequality? 


\section{Contribution}

- We develop a GE model in which inequality and segregation are both endogenous and feed on each other.

- High inequality, through housing prices, leads to higher residential segregation across different income groups.

- This change, in turn, creates wedge in the return from education of rich and poor families, amplifying differences in the investment in children's education

- The differential investment in children may in turn lead to even larger future inequality and low intergenerational mobility 


\section{Contribution}

- We develop a GE model in which inequality and segregation are both endogenous and feed on each other.

- High inequality, through housing prices, leads to higher residential segregation across different income groups.

- This change, in turn, creates wedge in the return from education of rich and poor families, amplifying differences in the investment in children's education

- The differential investment in children may in turn lead to even larger future inequality and low intergenerational mobility

The End of the American Dream? 


\section{Roadmap}

- Evidence on inequality and segregation

- inequality and segregation over time

- income segregation across US cities

- the empirical link between inequality and segregation

- A dynamic theory of inequality and segregation through residential and educational choices

- Evidence on the predictions of the model: a closer look to educational outcomes 


\section{Data and Sample Selection}

- Data

- Census data 1970 - 2000

- County-level and census tract-level tabulations of family income.

- Sample Selection

- 100 MSAs with largest population in 2000

- covers about 2/3 of all census tracts and about 2/3 of the number of families

- Measure of Inequality

- Gini coefficients: family income tabulated at county level aggregated to the MSA level 


\section{Measures of Segregation}

Figure: Trends in Residential Patterns, 1970-2000, 100 Largest MSA

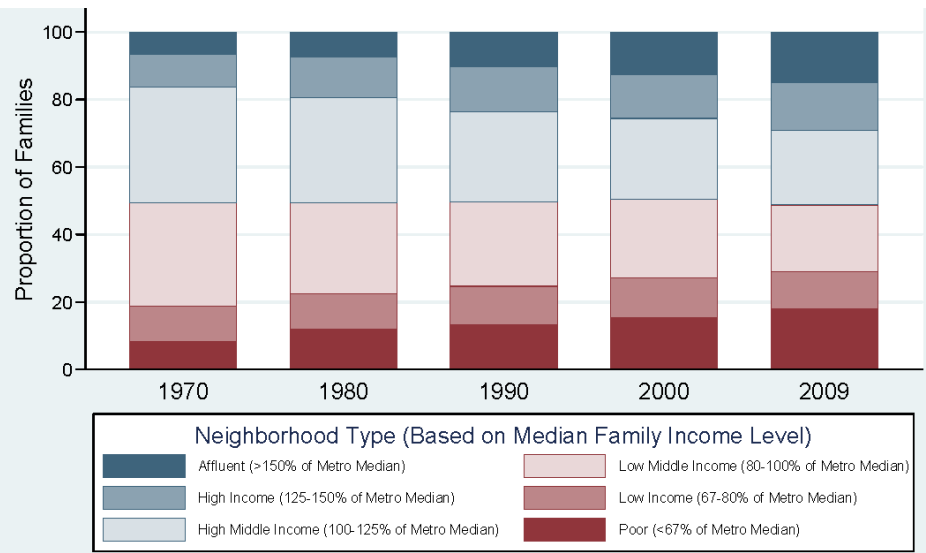

- Measure affected by income inequality 


\section{Rank Order Information Theory Index}

- $H_{k}$ measures the ratio of within unit (tract) income rank variation to overall (MSA) income rank variation.

- Let $p_{k}$ be a binary measure of income variation in a MSA (i.e. fraction of families earning less than $\mathrm{k}$ )

- Let $v_{k}=f\left(p_{k}\right)$ be a mapping from $[0,1]$ into $[0,1]$, s.t. $f(1 / 2)=1, f(1)=f(0)=0$.

- Let $v_{k, i}$ be the same index for Census tract $i$.

- The $H_{k}$ segregation index $=\sum_{i=1}^{N}\left(v_{k} \frac{T_{i}}{T\left(v_{k}-v_{k, i}\right)}\right)$ 


\section{Examples}

- $H_{10}$ Segregation of poverty:

if all CTs have the same fraction $\rightarrow$ no segregation

if all poor are concentrated in few CTs $\rightarrow$ max segregation)

- $H_{90}$ Segregation of affluence.

- $H_{R}=f\left(H_{10}, H_{20}, \ldots\right)$ weighted average of segregation at each point income distribution. Overall measure

- $H_{R}$ independent from inequality 


\section{Trend in Inequality and Segregation}

Figure: Trends in Family Income Inequality and Income Segregation, 1970-2000, 100 Largest Metropolitan Areas

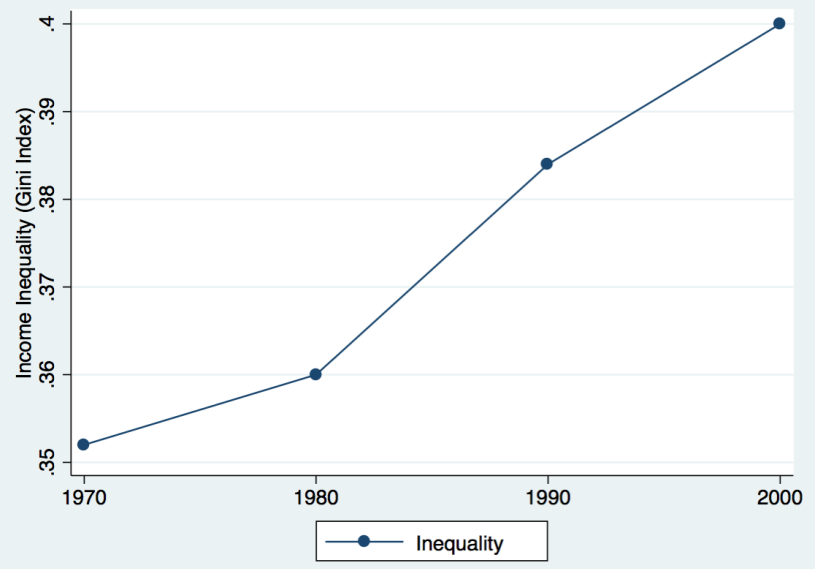




\section{Trend in Inequality and Segregation}

Figure: Trends in Family Income Inequality and Income Segregation, 1970-2000, 100 Largest Metropolitan Areas

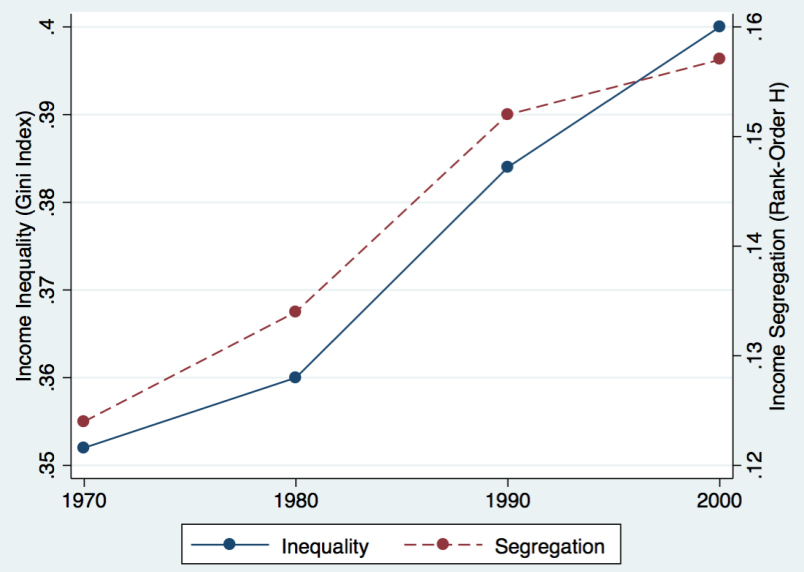




\section{Trend in Inequality and Segregation}

Figure: Trends in Average MSA Income Segregation, by Income Percentile, All Families, 100 Largest, 1970-2000

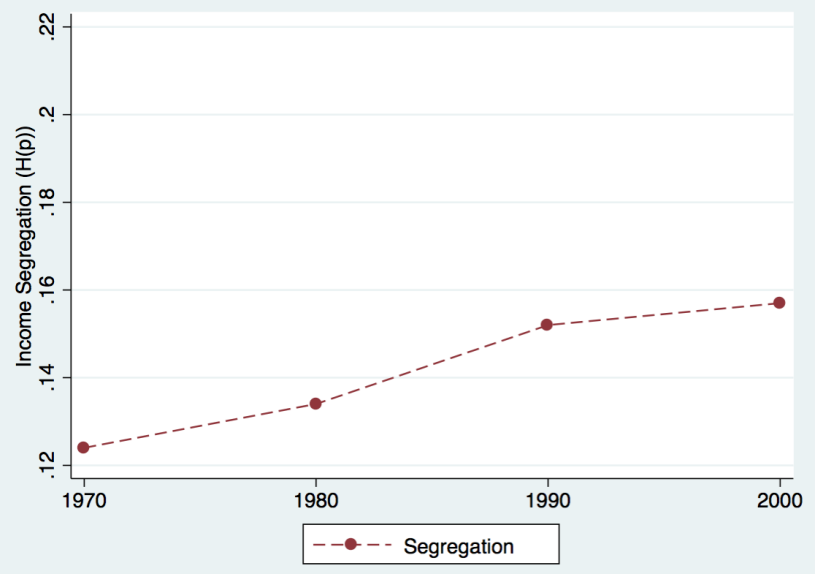




\section{Trend in Inequality and Segregation}

Figure: Trends in Average MSA Income Segregation, by Income Percentile, All Families, 100 Largest, 1970-2000

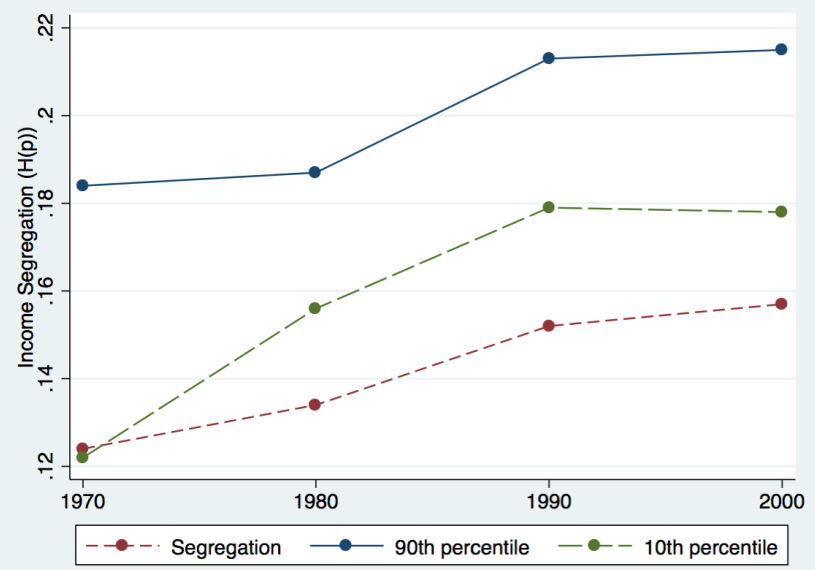




\section{The Geography of Segregation}

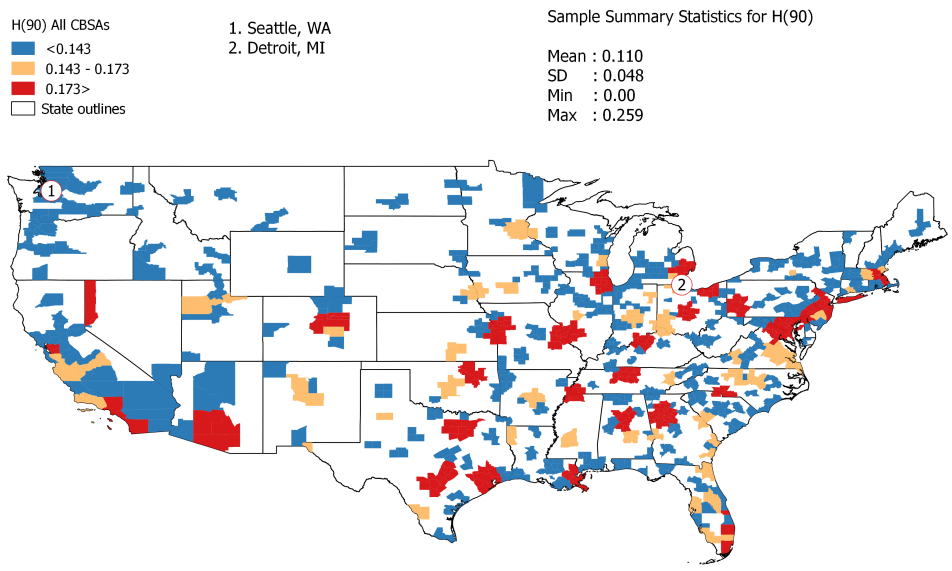




\section{The Geography of Segregation (Top 100)}

H(90) Top 100 CBSAs

$<0.143$

$0.143-0.173$

$0.173>$

$\square$ State outlines
1. Seattle, WA

2. Detroit, MI
Sample Summary Statistics for $\mathrm{H}(90)$

Mean : 0.121

SD : 0.046

Min : 0.04

Max : 0.259

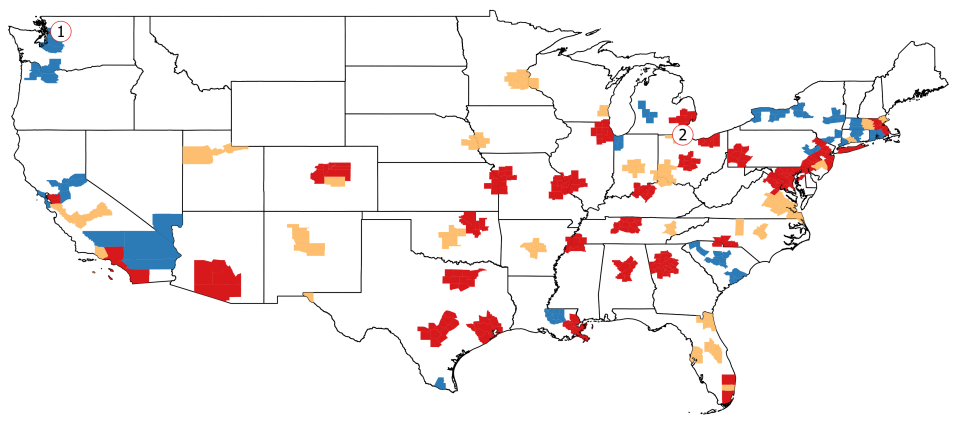




\section{Inequality and Segregation: Correlations}

By Decade

\begin{tabular}{|c|c|c|c|c|c|}
\hline & All Families & 1970 & 1980 & 1990 & 2000 \\
\hline Gini Index & $\begin{array}{l}0.561^{* * *} \\
(0.085)\end{array}$ & $\begin{array}{l}0.624^{*} \\
(0.268)\end{array}$ & $\begin{array}{l}0.649^{*} \\
(0.276)\end{array}$ & $\begin{array}{l}0.688^{* \star *} \\
(0.194)\end{array}$ & $\begin{array}{l}0.732^{* * *} \\
(0.153)\end{array}$ \\
\hline Year $=1980$ & $\begin{array}{l}0.027^{\star \star *} \\
(0.007)\end{array}$ & & & & \\
\hline Year $=1990$ & $\begin{array}{l}0.025^{\star} \\
(0.012)\end{array}$ & & & & \\
\hline Year $=2000$ & $\begin{array}{l}0.012 \\
(0.016)\end{array}$ & & & & \\
\hline Metro-Year Covariates & Yes & & & & \\
\hline Group-Metro-Year Covariates & & Yes & Yes & Yes & Yes \\
\hline Metro Fixed Effects & Yes & Yes & Yes & Yes & Yes \\
\hline Adjusted $R^{2}$ & 0.959 & 0.689 & 0.789 & 0.821 & 0.866 \\
\hline $\mathrm{N}$ & 400 & 161 & 161 & 161 & 161 \\
\hline
\end{tabular}

Note: Bootstrapped standard error in parentheses. ${ }^{*} p<.05 ;{ }^{* *} p<.01 ;{ }^{* * *} p<.001$. Sample includes observations from 100 largest metropolitan areas in 2000, excluding black observations from with fewer than 10,000 black families in 1970. Coefficients on covariates and fixed effects not shown. Metro-year covariates include metro population, unemployment rate, proportion under age 18, proportion over age 65, proportion with high school diploma, proportion foreign born, proportion female headed families, per capita income, proportions employed in manufacturing, construction, financial and real estate, professional and managerial jobs, and proportions of housing build within ten, five, and one years. Group-metro-year covariates include race-group-specific population, per capita income, proportion with high school diploma, proportion female headed families, and unemployment rate. 


\section{Takeways}

- Strong correlation between inequality and segregation

- It holds for levels and first differences

- Stronger in MSA with higher percentage of families with children 


\section{A Dynamic GE Theory of Inequality and Segregation}

- overlapping generations of agents who live for 2 periods: young and old

- when old, agents have a child with ability $a \sim G(a)$ iid

- two neighborhoods: $k \in\{A, B\}$

- old agent with wage $w$ and child ability $a$ at time $t$ chooses

- how much to consume $c_{t}(w, a)$

- in which neighborhood to live $k_{t}(w, a)$

- investment in child's education $e_{t}(w, a) \in\left\{e^{L}, e^{H}\right\}$ 


\section{Housing Market}

- houses are all of the same size and quality

- $R_{t}^{k}=$ rent in neighborhood $k$ at time $t$

- extreme assumptions on supply (to be relaxed!):

- fixed supply $H$ in neighborhood $A$;

- fully elastic supply of houses in neighborhood $B$;

- marginal cost of construction equal to $0 \Rightarrow R_{t}^{B}=0$ for all $t$

- $S_{t}^{k}=$ share of college educated agents in neighborhood $k$ at time $t$ 


\section{Wage distribution}

- initial wage distribution $F_{0}(w)$

- crucial: dynamics of wage distribution are endogenous!

- children wages affected by

- their ability a (random)

- their education $e$ (chosen by parents)

- their neighborhood's spillover $S^{k}$ (chosen by parents)

- spillover effect: quality of public school, peer effect, learning from neighbors' experience,...

- wage function:

$$
w_{t+1}=Q\left(a_{t}, e_{t}, S_{t}^{k}\right)
$$




\section{Optimization Problem}

- bequest motive: old agents care about their child's wage

- old agent $\left(w_{t}, a_{t}\right)$ at time $t$ solves

$$
\begin{aligned}
& U\left(w_{t}, a_{t}\right)=\max _{c_{t}, e_{t}, k_{t}} u\left(c_{t}\right)+g\left(w_{t+1}\right) \\
& \text { s.t. } c_{t}+R_{t}^{k_{t}}+\tau e_{t} \leq w_{t} \\
& w_{t+1}=Q\left(a_{t}, e_{t}, S_{t}^{k}\right)
\end{aligned}
$$

taking as given $R_{t}^{k}$ and $S_{t}^{k}$ for $k=A, B$ 


\section{Assumption}

\section{Assumption}

The function $Q\left(a, e, S^{k}\right)$ has increasing differences in $\left(a, S_{k}\right)$ and in $\left(e, S^{k}\right)$, that is, for $a^{\prime}>a, e^{H}>e^{L}$, and $S^{A}>S^{B}$,

$$
Q\left(a^{\prime}, e, S^{A}\right)-Q\left(a^{\prime}, e, S^{B}\right) \geq Q\left(a, e, S^{A}\right)-Q\left(a, e, S^{B}\right) \text { for any e, }
$$

and

$Q\left(a, e^{H}, S^{A}\right)-Q\left(a, e^{H}, S^{B}\right) \geq Q\left(a, e^{L}, S^{A}\right)-Q\left(a, e^{L}, S^{B}\right)$ for any a. 


\section{Cut-off Characterization}

\section{Proposition}

If $S^{A}>S^{B}$, there are two cut-off functions $\hat{w}_{t}(a)$ and $\hat{\hat{w}}_{t}(a)$ such that

$$
e_{t}\left(w_{t}, a_{t}\right)=\left\{\begin{array}{l}
0 \text { if } w_{t}<\hat{w}_{t}\left(a_{t}\right) \\
1 \text { if } w_{t} \geq \hat{w}_{t}\left(a_{t}\right)
\end{array},\right.
$$

and

$$
k_{t}\left(w_{t}, a_{t}\right)=\left\{\begin{array}{l}
B \text { if } w_{t}<\hat{\hat{w}}_{t}\left(a_{t}\right) \\
A \text { if } w_{t} \geq \hat{\hat{w}}_{t}\left(a_{t}\right)
\end{array} .\right.
$$




\section{Cut-off Characterization (continued)}

- neighborhood A is the "good" one $=S_{t}^{A}>S_{t}^{B} \Rightarrow R_{t}^{A}>R_{t}^{B}$

- assume for simplicity $Q\left(a, e^{L}, S^{k}\right)$ is independent of $S^{k}$

- $\Rightarrow$ never optimal to choose neighborhood $\mathrm{A}$ and low education

- $\Rightarrow$ old agents have three options:

1. neighborhood $A$ and high education $\left(w \geq \hat{\hat{w}}_{t}(a)\right)$

2. neighborhood $B$ and high education $\left(\hat{w}_{t}(a) \leq w<\hat{\hat{w}}_{t}(a)\right)$

3. neighborhood $B$ and low education $\left(w<\hat{w}_{t}(a)\right)$ 


\section{Static Equilibrium}

For given $F_{t}(w)$, a static equilibrium is two cutoff functions $\hat{w}_{t}\left(a_{t}\right)$ and $\hat{\hat{w}}_{t}\left(a_{t}\right)$ and four scalars $R_{t}^{A}, R_{t}^{B}, S_{t}^{A}$ and $S_{t}^{B}$ such that

- agents optimize taking as given rents and spillovers

- housing markets clear: $R_{t}^{B}=0$ and $R_{t}^{A}$ such that

$$
\int\left[1-F_{t}\left(\hat{\hat{w}}_{t}\right)\right] d G\left(a_{t}\right)=H ;
$$

- spillover effect consistent with equlibrium: $S_{t}^{A}=1$ and

$$
S_{t}^{B}=\frac{\int\left[F_{t}\left(\hat{\hat{w}}_{t}\left(a_{t}\right)\right)-F_{t}\left(\hat{w}_{t}\left(a_{t}\right)\right)\right] d G\left(a_{t}\right)}{\int F_{t}\left(\hat{\hat{w}}_{t}\left(a_{t}\right)\right) d G\left(a_{t}\right)} .
$$




\section{Dynamic Equilibrium}

A dynamic equilibrium is a sequence of static equilibria and a law of motion for $F_{t}$ given by

- an initial condition $F_{0}(w)$

- the evolution of the intergenerational wages

$$
w_{t+1}\left(w_{t}, a_{t}\right)=Q\left(a_{t}, e_{t}\left(w_{t}, a_{t}\right), S_{t}^{k_{t}\left(w_{t}, a_{t}\right)}\right)
$$




\section{Numerical Example}

- 2 periods (full dynamics coming soon!)

- choose $u(c)=\log (c)$ and $g(c)=c$

- set $e^{L}=0$ and $e^{H}=1$

- ability distribution $G(a)$ lognormal

- initial wage distribution $F_{0}(w)$ lognormal

- wage function

$$
Q\left(a, e, S^{k}\right)=a+a e\left(\beta_{0}+\beta_{1} S^{k}\right)
$$




\section{Partial vs Full Segregation}

- remember that all agents in neighborhood $\mathrm{A}$ have high education: $S^{A}=1$

- 2 possible scenarios:

1. partial segregation: $\hat{w}_{t}\left(a_{t}\right)<\hat{\hat{w}}_{t}\left(a_{t}\right)$

- neighborhood $\mathrm{B}$ has some agents with high and some with low education $\Rightarrow 0<S^{B}<1$

2. full segregation: $\hat{w}_{t}\left(a_{t}\right)=\hat{\hat{w}}_{t}\left(a_{t}\right)$

- all agents in neighborhood $B$ have low education $\Rightarrow S^{B}=0$ 


\section{Time 0: Partial Segregation}

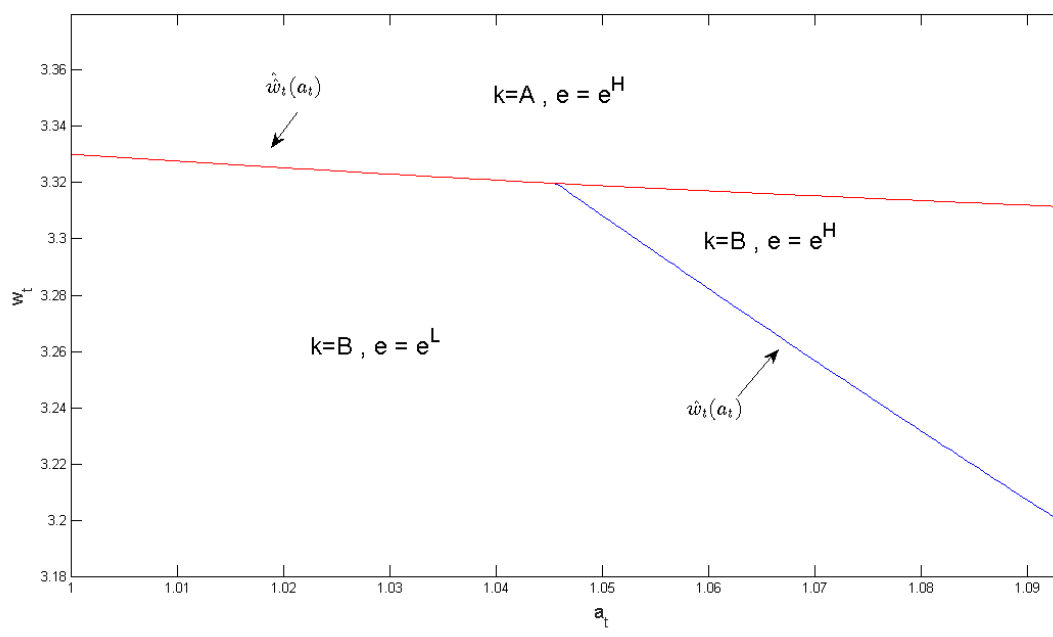




\section{Segregation and Inequality}

- $F_{0}(w)$ such that there is partial segregation at time 0

- partial segregation $=$ higher return on education in neighborhood $\mathrm{A}$ than $\mathrm{B}$

- moreover richer agents live in neighborhood $\mathrm{A}$

- $\Rightarrow$ increase in inequality and reduction in intergenerational mobility

- $\Rightarrow$ even more segregation

- in our example: switch to full segregation in 1 period! 


\section{Increase in Inequality}

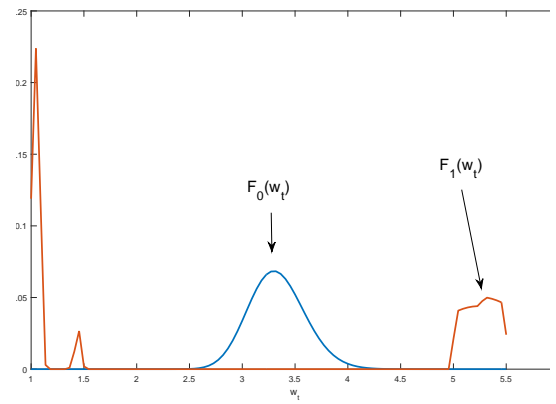




\section{Time 1: Full Segregation}

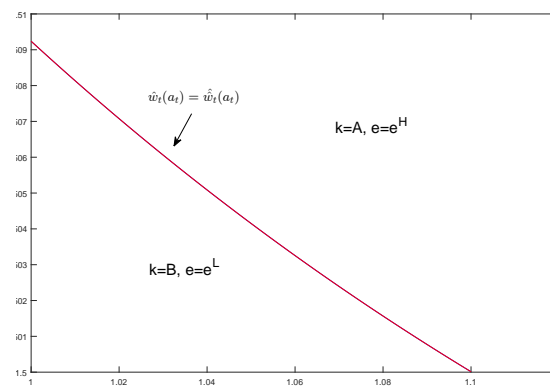




\section{Dynamic Implications}

- Rich and poor have different educational attainments

- This implies that, as inequality increases, attainment gap increases

- Key point is that increase in segregation amplifies the impact of inequality on educational attainment gap

- Segregation is powerful force in making inequality higher and more persistent 


\section{Stanford Education Data Archive (SEDA)}

- Average district-level standardized test scores (on state accountability tests)

- 11,280 geographic school districts (including charter schools)

- Grades 3-8

- Math \& ELA

- 2009 - 2013 (10 cohorts of students entering K in 2000 2009)

- Based on 215,000,000 test scores

- Scores are placed on common scale across states, years, and grades

- Demographic data

- Family characteristics (of families with children in public schools)

- From American Community Survey (ACS) 


\section{Some direct evidence: across districts}

\section{Large achievement gap between rich and poor}

\section{Educational attainment in each school district in the U.S.}




\section{Some direct evidence: across time}

This gap has increased over time

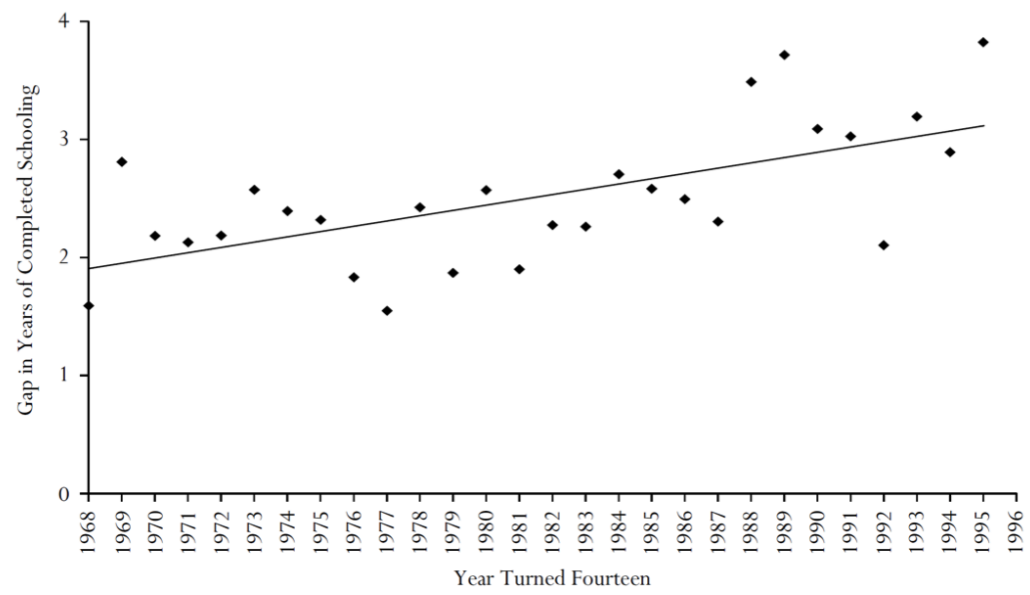




\section{Segregation Amplifies Achievement Gap H90}

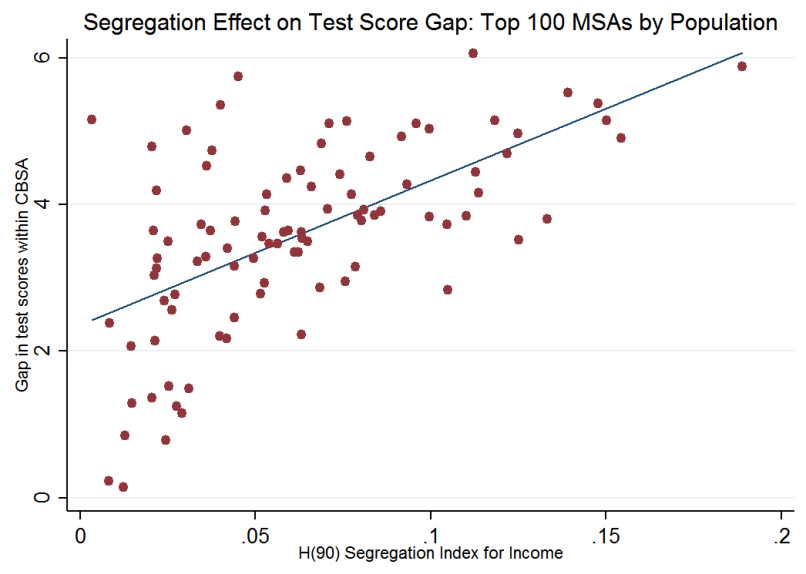




\section{Segregation Amplifies Achievement Gap H90}

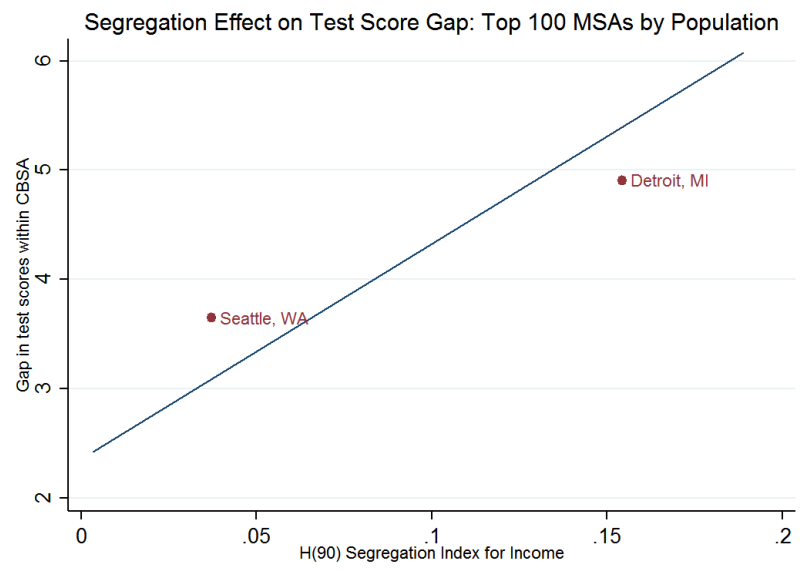




\section{Segregation Amplifies Achievement Gap H10}

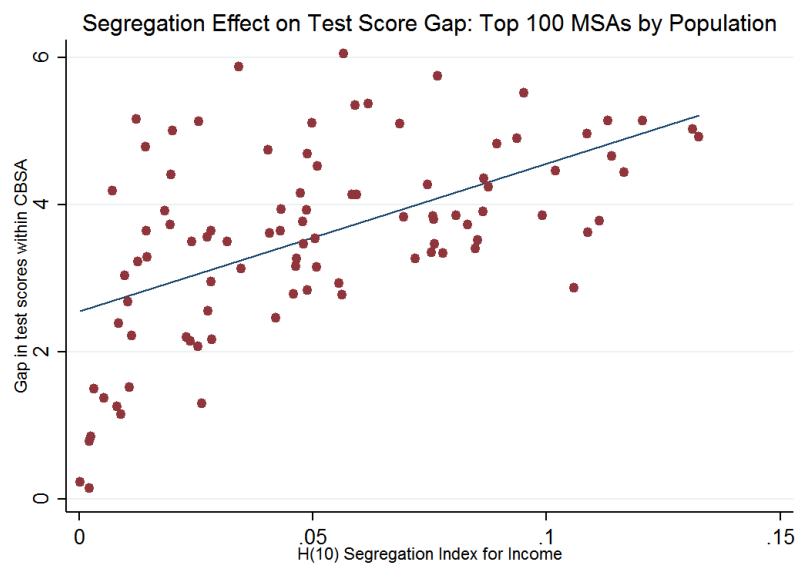




\section{Segregation Amplifies Achievement Gap H10}

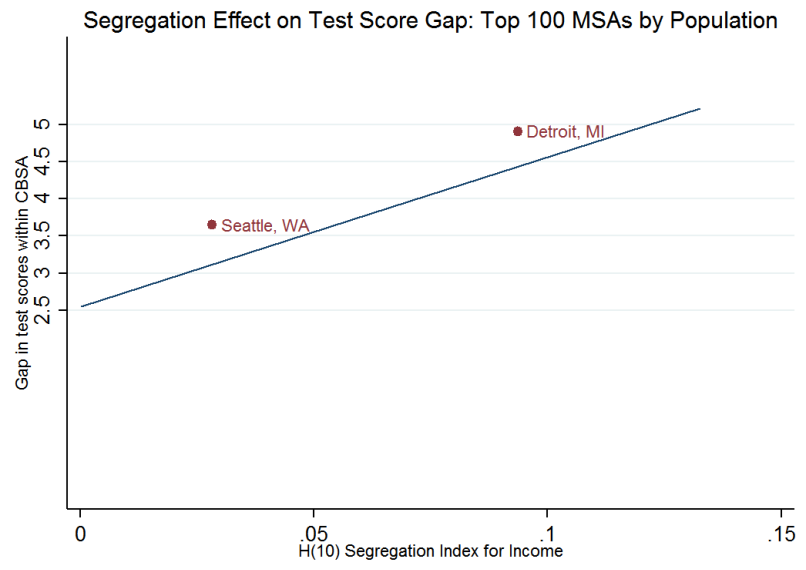




\section{The End of the American Dream?}

\section{More millennials say American dream is "not really alive"}

Q: Do you personally feel that The American Dream is very much alive today, somewhat alive, or not really alive? \% saying "not really alive" among those ages $18-35$

$1986-2015$

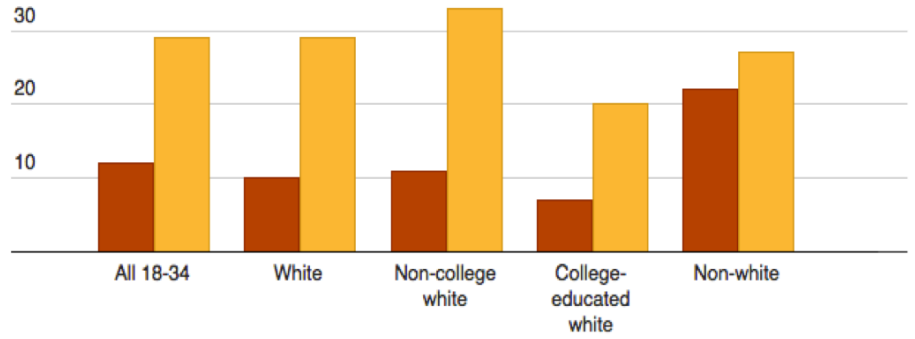




\section{Summary Statistics}

In 2000, our subsample of 100 MSAs contains:

- $66 \%$ of the total number of families for whom income is tabulated.

- $18 \%$ of all counties in the U.S.

- $67 \%$ of all census tracts in the U.S.

- $36 \%$ of all MSAs in the U.S. 


\section{Measuring Income Segregation}

- Let $p_{k}$ be a binary measure of income variation in a MSA (i.e. fraction of families earning less than $\mathrm{k}$ )

- Let $v_{k}=f\left(p_{k}\right)$ be a mapping from $[0,1]$ into $[0,1]$, s.t. $f(1 / 2)=1, f(1)=f(0)=0$. (variation is maximal when $p=1 / 2$ and minimal when $p=1$ or $p=0$.)

- Let $v_{k, i}$ be the same index for Census tract $i$.

- The $H_{k}$ segregation index $=\sum_{i=1}^{N}\left(v_{k} \frac{T_{i}}{T\left(v_{k}-v_{k, i}\right)}\right)$

- Independent from income inequality 


\section{Examples}

- $H_{10}$ segregation of poverty: measures differences (across $\mathrm{CT}$ ) in fraction of of families living below the MSA 10th income percentile. (I.e. If all CTs have the same fraction $\rightarrow$ no segregation, if all poor are concentrated in few CTs $\rightarrow$ max segregation)

- $H_{90}$ Segregation of affluence

- $H_{R}=f\left(H_{10}, H_{20}, \ldots\right)$, captures overall segregation

- Time trends are unweighted averages 